[Letter]

\title{
Application of Logistic Regression Analysis to Combustion of Toluene over $\gamma$-Alumina-supported Platinum Catalyst
}

\author{
Hideo Nagata*, Sakiho Izumi, Rina Yamashita, Yuki Johno \\ Dept. of Chemical and Biological Engineering, National Institute of Technology, Sasebo College, \\ Okishin-cho, Sasebo, Nagasaki 857-1193, JAPAN
}

(Received April 22, 2021)

\begin{abstract}
Catalytic combustion of an organic compound is characterized by an S-shaped curve for the temperature dependence of the reaction. Expression of this S-shaped curve with a mathematical function would allow highly accurate analysis based on a small number of data points. This study used toluene combustion over a $\gamma-$ alumina-supported platinum catalyst as an example of a catalytic combustion reaction, and investigated whether the temperature dependence of the toluene conversion could be expressed by a logistic function. The parameters were obtained from the reaction data using a single regression analysis. The logistic function well represented the experimental data using the linear relationship as the function of temperature. Furthermore, the temperature at which the toluene conversion reaches $50 \%$ can be objectively determined.
\end{abstract}

Keywords: Toluene combustion, Logistic regression analysis, Platinum catalyst

\section{Introduction}

Catalytic combustion of an organic compound typically proceeds at a very high reaction rate, so the differential reactor method that is often used in reaction engineering is rarely employed to study such reactions. Generally, the catalytic performance and reactivity associated with a catalytic combustion reaction are assessed based on the temperature at which $50 \%$ conversion is achieved $\left(T_{50}\right)$. This $T_{50}$ value is obtained from a graph of the reactant conversion as a function of temperature. Such plots are often generated manually, but this process introduces subjective interpretations. Plots of conversion versus temperature are generally fit using an S-shaped curve, so a significant number of data points are required to accurately determine $T_{50}$.

\footnotetext{
DOI: doi.org/10.1627/jpi.64.340

“ $\gamma$-アルミナ担持白金触媒によるトルエン燃焼

反応へのロジスティック関数の適用”

長田秀夫*, 出水咲帆, 山下莉奈, 城野祐生

佐世保工業高等専門学校物質工学科, 857-1193

長崎県佐世保市沖新町 1-1

*Corresponding author, E-mail: nagata@sasebo.ac.jp
}

However, representation of this S-shaped curve by a mathematical function would allow highly accurate determination of $T_{50}$ with a smaller quantity of data.

In the field of mathematics, the S-shaped curve is represented by a sigmoid function. Sigmoid functions include logistic functions, cumulative normal distributions, Gompertz functions, and Gudermannian functions. Of these, the logistic function, also called the standard sigmoid function, is the simplest and is expressed by the following Eq. (1) ${ }^{1), 2}$.

$$
y=\frac{1}{1+\exp (-f(x))}
$$

Here, $f(x)$ represents a function of $x$, and exp represents a power of the Napier number. Figure 1 shows the case of $f(x)=x$ as a typical logistic function. As $x$ changes from $-\infty$ to $+\infty, y$ changes from 0 to 1 . The logistic function is not often used in the field of chemistry, but is often used in fields such as sociology ${ }^{3)}$, economics ${ }^{4}$, and medicine ${ }^{5)}$ Logistic functions have been used to describe autocatalytic reactions and rate analysis of secondary reactions with two types of reactants ${ }^{6}$. In addition, logistic functions were applied to the results of bioassays ${ }^{7)}$. A logistic function was also applied to the autocatalytic reaction represented by the extended Prout- 


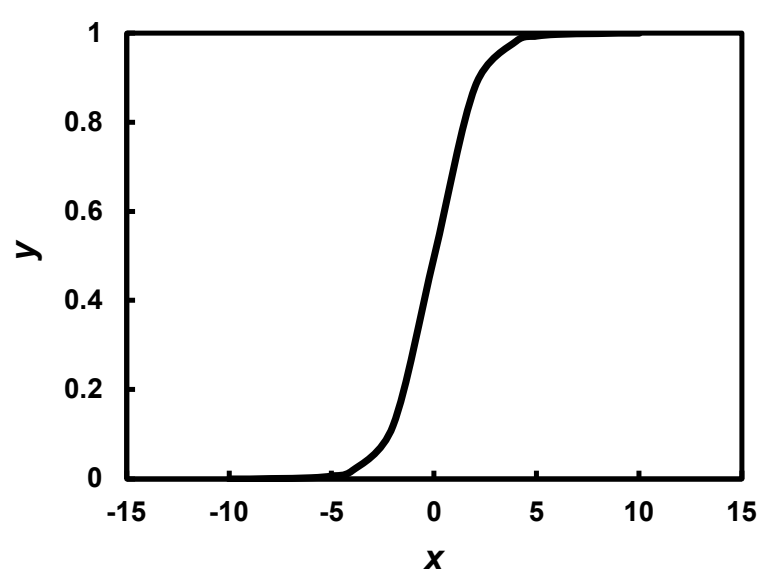

Fig. 1 Plot of Typical Logistic Function

Tompkins model to analyze the results of thermal analysis ${ }^{8)}$. The logistic function is effective for regression analysis of discrete values, but can also be applied to continuous values as used for analysis of reaction rate $^{6)}$.

We applied the simplest logistic function of the sigmoid functions to the process of synthesizing MFI-type silicalite ${ }^{9)}$. Using $f(x)$ as a continuous value function of time $(f(t))$ and the logarithmic function $a \ln (t)+b(a$ and $b$ are fitting parameters) described the process of crystallization. The time dependence of degree can be expressed with good correlation, and the length of the induction period and the crystal growth rate can be objectively obtained using the parameters $a$ and $b$. Therefore, this study used the combustion reaction of toluene with $\gamma$-alumina-supported platinum catalyst as an example of the catalytic combustion reaction, to investigate whether the temperature dependence of the reaction can be expressed by the simplest of the sigmoid functions.

\section{Experimental}

\subsection{Catalyst Preparation}

$\gamma$-Alumina-supported platinum catalyst was prepared by the impregnation method. Tetraamminedichloroplatinum $5 \%$ aqueous solution (TANAKA Kikinzoku Kogyo K.K.) was used for impregnation of $\gamma$-alumina (JGC Catalysts and Chemicals Ltd.) at $453 \mathrm{~K}$. The product containing $1 \%$ platinum was calcined at $673 \mathrm{~K}$ for $1 \mathrm{~h}$ in an air stream (100
$\mathrm{mL} / \mathrm{min}$ ).

\subsection{Reaction Procedure}

Catalytic combustion of toluene was carried out using a fixed bed atmospheric pressure flow reactor with a quartz reaction tube filled with $0.2 \mathrm{~g}$ of catalyst. The reaction gas with a toluene concentration of $1000 \mathrm{ppm}$ was introduced into the catalyst layer by passing air (100 $\mathrm{mL} / \mathrm{min}$ ) through a saturation device at $238 \mathrm{~K}$ containing toluene (Wako Pure Chemical Industries, Ltd., special grade). The temperature of the catalyst layer was raised in increments of 25 to $373 \mathrm{~K}$, and the product gas was manually sampled each time and analyzed with an FID type gas chromatograph GC-14B (Shimadzu Corpn).

\subsection{Logistic Regression Analysis}

The logistic function was applied to the experimental results based on a previously reported method ${ }^{10)}$. In the logistic function (Eq. (1)), the independent variable $(x)$ is defined as the reaction temperature $(T[\mathrm{~K}])$, the dependent variable $(y)$ is defined as the conversion ratio $\left(x_{\mathrm{A}}[\%]\right)$, and $f(T)$ is defined as the linear function $\beta_{0}+\beta_{1} T$ ( $\beta_{0}$ and $\beta_{1}$ are fitting parameters), such that:

$$
x_{\mathrm{A}}=\frac{100}{1+\exp \left(-\beta_{0}-\beta_{1} T\right)} .
$$

This equation is then rearranged to give

$$
\ln \left(\frac{x_{\mathrm{A}}}{100-x_{\mathrm{A}}}\right)=\beta_{0}+\beta_{1} T
$$

The term $x_{\mathrm{A}} /\left(100-x_{\mathrm{A}}\right)$ is referred to as the odds in the field of mathematics, and the left hand side of the above equation is referred to as log odds. The parameters $\beta_{0}$ and $\beta_{1}$ could be obtained from the reaction data using a single regression analysis.

\section{Results and Discussion}

\subsection{Toluene Combustion}

Figure 2 shows the conversion data obtained as the reactor temperature was increased, and confirms that the data describe an S-shaped curve. These data were used together with Eq. (3) to perform a simple regression analysis, the results of which are provided in Fig. 3. The resulting value for the coefficient of determination $\left(R^{2}\right)$ was 0.99 , indicating a high degree of correlation. 


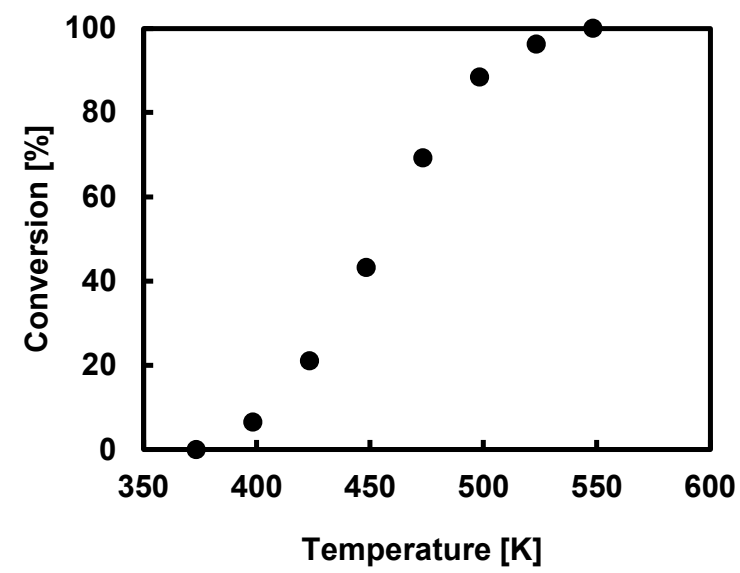

Fig. 2 Temperature-dependence of Toluene Conversion for Toluene Combustion

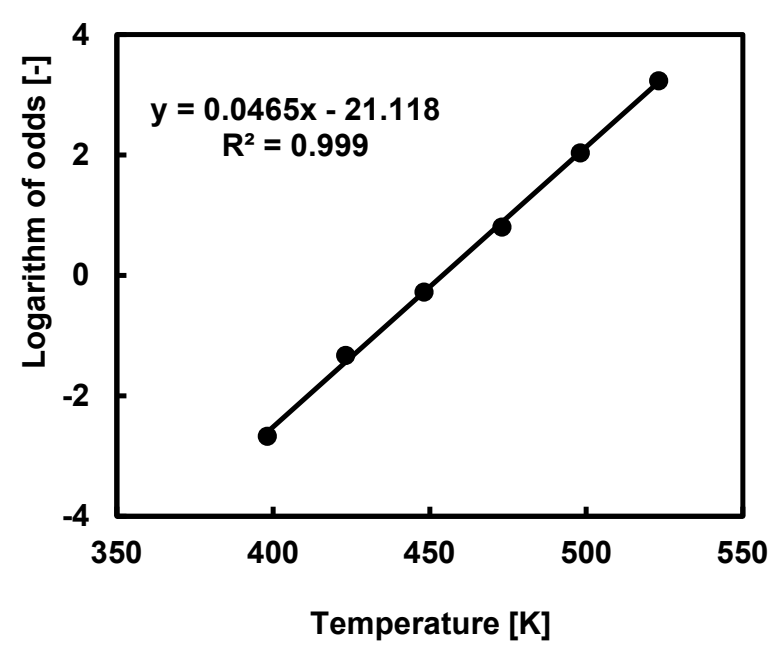

Fig. 3 Relationship between Logarithm of Odds and Temperature

Figure 4 presents the results obtained by substituting the parameters generated from this regression analysis into Eq. (2), and compares these values with the actual experimental data. This plot demonstrates that the logistic function provided a good representation of the experimental data. In each case, the coefficient of determination was at least 0.99 and no significant differences were observed between the y intercept and slope values.

\subsection{Logistic Regression Analysis}

The $T_{50}$ values for these trials were calculated using the regression parameters by substituting $x_{\mathrm{A}}=50.0$ into Eq. (3) to give an odds value of 1 . Consequently, a log

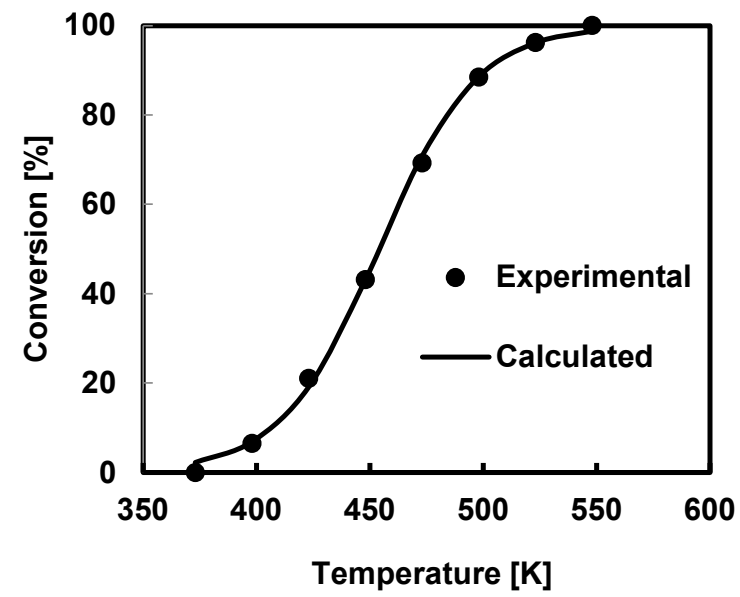

Fig. 4 Comparison between Experimental Data and Regression Analysis

odds value of 0 was obtained and the right hand side of the equation also had a value of 0 . Thus, $T_{50}$ could be determined as $-\square_{1} / \square_{0}$, and the difference in the reaction results could be objectively compared. The value of $T_{50}$ calculated based on the results of the repeat experiments was $453 \pm 4 \mathrm{~K}$.

The effects of the regression parameters $\beta_{0}$ and $\beta_{1}$ on the reaction results were also examined. A linear relationship between the conversion ratio and the reaction temperature $\left(x_{\mathrm{A}}=a+b T\right)$ was assumed and the slope, $b$, could therefore be determined as the derivative with respect to temperature at $T_{50}$, as

$$
\frac{d x_{\mathrm{A}}}{d T}=\frac{100 \beta_{1} \exp \left(-\beta_{0}-\beta_{1} T\right)}{\left\{1+\exp \left(-\beta_{0}-\beta_{1} T\right)\right\}^{2}}
$$

Substituting $T_{50}=-\beta_{1} / \beta_{0}$ into this equation gave $b=25 \beta_{1}$. In addition, since $x_{\mathrm{A}}=a+b T$ passes through the point $\left(T_{50}, 50\right), a=50-25 \beta_{0}$. That is, a smaller value of $\beta_{1}$ corresponds to a less rapid increase in conversion ratio with increasing reaction temperature, while a larger $\beta_{0}$ value indicates a greater degree of conversion at a lower temperature as shown in Fig. 5.

The above results confirm that the temperature dependence of the conversion ratio during toluene combustion over a $\gamma$-alumina-supported platinum catalyst can be expressed by a logistic function. This permits an objective assessment of $T_{50}$, which is an index of reactivity, using the regression parameters. 


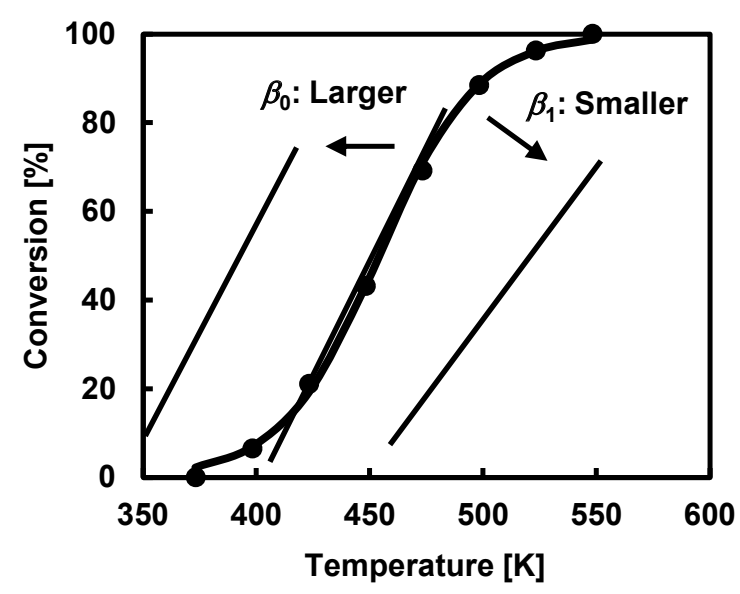

Fig. 5 Schematic Diagram when $\beta_{0}$ and $\beta_{1}$ Change

\section{Acknowledgment}

This research was supported in part by a Grant-in-Aid for Scientific Research (C) (No. 18K03961) from the Japan Society for the Promotion of Science.

\section{References}

1) Verhulst, P.-F., Correspondance Mathématique et Physique, 10, 113 (1938).

2) Verhulst, P.-F., Nouveaux Mémoires de l'Académie Royale des Sciences et Belles-Lettres de Bruxelles, 18, 1 (1845).

3) Mood, C., European Sociological Review, 26, 67 (2010).

4) Javanovic, B., Rob, R., Review of Economic Studies, 56, 569 (1989).

5) Boateng, E.Y., Abaye,, D., J. Data Anal. Inform. Processing, 7, 190 (2019).

6) Reed, L.J., and Berkson, J., J. Phys. Chem., 33, 760 (1929).

7) Burnham, A.K., J. Therm. Anal. Calor., 127, 1107, (2017).

8) Berkson, J., J. Am. Stat. Assoc., 39, 357 (1944).

9) Nagata,, H., Kawahara, S., Watanabe, T., Tanaka, Y., Hamada, H. , J. Jpn. Petrol. Inst., 63(1), 38 (2020).

10) Cox, D.R., J. Roy. Stat. Soc. B, 20, 215 (1958). 